\title{
Analysis on the Problems in Online Shopping Under Prisoners Dilemma
}

\author{
He Sun*1 \\ ${ }^{1}$ Queen Ethelburga's College \\ *Corresponding author. Email: hesun1226@sina.com

\begin{abstract}
This paper analyzes the dispute between e-commerce sellers, the managers of e-commerce platform and the buyers according to game theory in 4 different online trading situation. This paper concludes that there is a motivation for each group of people mentioned above to cheat, however, we can improve the online trading system by providing clearer information and the power of related regulator.
\end{abstract}

Keywords: Online shopping, Prisoners dilemma, E-commerce, Cheat and trust

\section{INTRODUCTION}

Online shopping is a popular way of shopping in every part of the world now. According to the China Ecommerce Center's 2019 China E-commerce Annual Data, the market size of e-commerce transactions in 2019 ranked first in the world [1]. Especially during the period of COVID-19 virus, e-commerce industry has shown its power and importance and become a significant part of modern economy. However, there are usually some problems during the trading process, for example, false advertising or selling goods which lower than the standard quality, because there is distance between consumers and the sellers, so consumers can not see the actual state of the product which they wish to buy.

This paper analyzes the behaviour and choices between consumers and the managers of e-commerce according to the game theory, thus, provide possible solutions to reduce the problems caused by lack of trust between consumers and sellers to improve the ecommercial environment and give a better online shopping experience for everyone.

\section{BACKGROUND}

With the rapid development of China's Internet technology and the steady growth of Chinese residents' disposable income, online shopping has become an indispensable consumption channel for Chinese Internet users, and online shopping users are spending more and more money on online shopping.

Data shows that from 2013 to 2018 , the value of online shopping transactions in China increased from 267.9 billion yuan to 5,737 billion yuan, a compound growth rate of $84.6 \%$; it is expected that in 2019 , the value of online shopping transactions will reach 6661.0 billion yuan. 


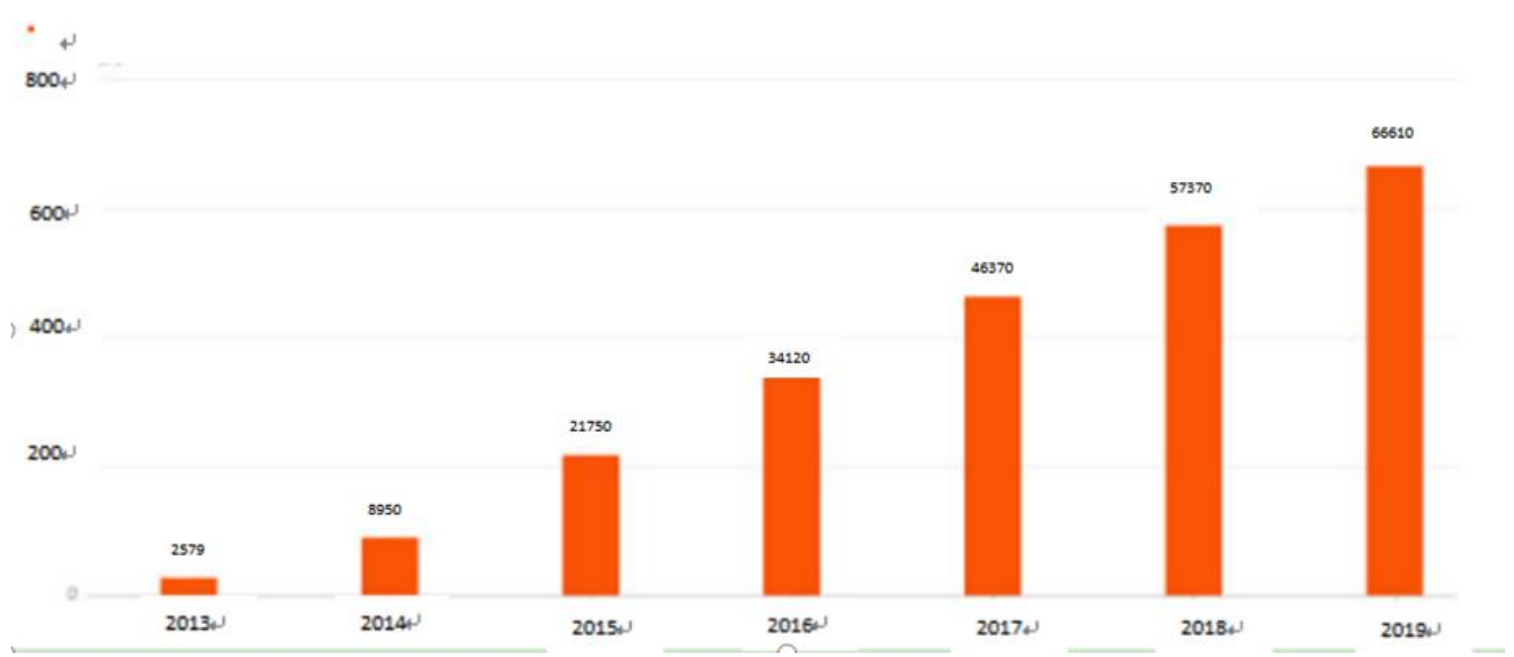

Figure 1. 2013-2019 China online shopping transaction value (unit: hundred million)

\section{THE MODEL OF GAME THEORY}

This situation can be assumed as a Prisoners Dilemma game. In this game, buyers and sellers are the two sides of the players. Both of them are rational and selfinterested. Additionally, each group of the buyers and sellers play the game once and they will change their partner in the next game. Also, it is assumed that buying and selling the good happens at a same time.

There are 4 consequences of the game: 1. The consumer choose to buy and the seller choose to be honest, the consumers will get a benefit of a and the sellers will get a benefit of $b$

2. The consumer choose not to buy and the seller choose to be honest, the trade do not exist in this case, so both of them will get 0 profit

3 . The consumer choose to buy and the seller choose to cheat, the good which consumers actually get will not as good as they expected, so they will get a benefit of $c$, the benefit of sellers will be e-d because there is a cost of cheating

4. The consumer choose not to buy and the seller choose to cheat, the trade do not exist but there will be a cost of cheating for sellers

Table1. The payoff matrix between buyers and sellers

\begin{tabular}{|l|l|l|}
\hline Sellors Consumers & Buy & Do not Buy \\
\hline Be honest & & \\
\hline Cheat & $(a, b)$ & $(0,0)$ \\
\hline e-d $>$ a & $(e-d,-c)$ & $(-d, 0)$ \\
\hline
\end{tabular}

The dominant stratege for consumers is buy, and the dominant strategy for sellers is cheat because both of them aim for higher profit. Thus, this will lead to a Nash equilibrium of choosing(buy, cheat). Which means the welfare of the consumers will be hurt [3].

So the purpose of doing this research is to analyse why those problems mentioned above happens and provide suitable solutions to reduce the welfare loss of both consumers and sellers. Thus, achieve a more mature system of online shopping and benefit the society.

\section{UNRELIABLE COMMENTS}

People sometimes choose to consume a product by reading through the comment [2]. In this case, some sellers may increase the number of positive comment by illegal tools, for example, creating false volume and fake order and paying for some people or using technologh ways to leave positive comments for these orders to attracting buying or selling interest.

However, this is not only unfair in competition between different online sellers, but also has negative effects to consumers. Because those fake comments can not reflect the real state and quality of a product, thus, consumers will get the wrong information, they may recognise the good which they bought is not as good as it has been shown on the website. So, this will be an awful experience of online shopping, the consumer benefits are reduced. But the profit of the sellers increased because they sell more goods.

The situation mentioned above can be modelled as a static game theory as well.

\section{UNRELIABLE DESCRIPTION OF THE PRODUCT}

Apart from leaving fake comments, some sellers on the e-commerce platform may also provide a unreliable description of the product selling which they are selling 
[6]. For example, some sellers on the second-hand trade platform may conceal the true state of the goods, like saying that a old shirt is new to let the consumers to buy. There will certainly be a welfare loss of consumers because they can not get want they want. The reason why it happens is that there is assymetric information between consumers and the sellers. People who sell the good have more knowledge than those who wish to buy it.

One possible way to reduce the loss of consumers is to set up a mature returning system. The platform will hold and the sellers can not get the money until the consumers get the product and saying that it is as good as it has been shown on the platform. If it has been proved by sending photos or videos that the sellers has delivered goods in bad quality, they will never get the money, and it will be returned to the consumers.

\section{GAME BETWEEN DIFFERENT SELLERS}

We assumed that every single seller is rational, selfinterested and aim for maximise profit. Each of them do not know what their competitor will choose. The ecommerce platform will punish the seller who make fake comments. There are 3 consequences of this game: 1 . Both of them will make a fake comment 2. One of them will make a fake comment 3 . Both of them will not make a fake comment. The Nash equilibrium of this game the third one because both of them will not punished by the e-commerce platform and earning 0 profit.

However, they may choose to leave fake comment because it will help them to attract more customers and increase sales volumn, especially for some new brands.

\section{GAME BETWEEN THE SELLERS AND THE E-COMMERCE MANAGERS}

We assumed that each of them is rational, selfinterested and aim for maximised profit, and each of them will make the decision independently

There are 4 consequences of the game: 1 . The seller choose to lie and the platform choose to punish 2 . The seller choose to tell the truth and the platform choose to punish 3. The seller choose to lie and the platform choose not to punish 4 . The seller choose to tell the truth and the platform choose not to punish. There is no dominant stratege for this situation and there is no Nash equilibrium.

\section{THE CONSEQUENCE CAN BE DIFFERENT WHEN THEY ARE PLAYING REPEAT GAMES}

When the game is repeated, people may choose to trust in the second period of the game if their partner also telling the truth, otherwise, they may never telling the truth. This means consumers may consume a same product twice or buying things in a same online shop twice if they have a good experience at the first consumption, otherwise, they may never spend money at the same place.

In this case, always telling the truth will help the seller to catch customers, which means it will help them to make a profit in the future. Ones who selling goods with a same quality as they have advertised will make more profit in the future.

According to the repeated game theory, it will be a good choice for the e-commerce manager to set a credit system to ensure that all the actions of the sellers and their credit related informations are open to the customers.

\section{SOLUTIONS}

According to the researches I have done, the possible solutions I would provide are as follows: Firstly, we can increase the power of authorties by making a more detailed e-commercial law. The authorties could fire those who break the law [5]. Also, increasing the intensity of punishment may encourage the sellers to run their business honestly and focus on the long term profit ,such as image of the brand not the short term profit, as they can not afford the cost of cheating(4) Moreover, setting a credit system may be useful. It will be more expensive for some business with low credit to cheat and using illegal toots like fake comments and trading to increase their credit. So they make think about how to improve their quality of the product instead of using different ways to cheat. Finally, we can provide a fully information system and let consumers learn more detail of the product, this will help them to choose and reduce the negative effect of asymmetric information

\section{CONCLUSION}

This paper is aiming for analysing the conflicts between the buyers, sellers and the ecommerce platform managers during the online shopping process. By setting the model of game theory, considering the situation of unreliable comments and description of the products made by the sellers to increase sales, I also analyse the different choices that the players will make when they are playing repeat games and concludes that if the buyers and sellers know they will trade twice or more times in the future, there will be a motivation for them to cooperate. In conclution, we can give solutions to improve the online trading environment by promoting them to trade for more times and increase the power of authorities. Because the the game theory always tells us that cooperation will make higher profit. 


\section{ACKNOWLEDGMENT}

First and foremost,I would like to show my deepest gratitude to my teachers and professors in my university, who have provided me with valuable guidance in every stage of the writing of this thesis. Further,I would like to thank all my friends and roommates for their encouragement and support.Without all their enlightening instruction and impressive kindness,I could not have completed my thesis.

\section{REFERNECES}

[1] China E-commerce Report (2019) source: Department of E-commerce and Information Technology, Ministry of Commerce, 2020-07-02 15:04

[2] Zheng Lei, Yu mengxiao, Zhang Lefan. Business Ethics under Big Data: Analysis on Dishonest Behavior of E-commerce ( $\mathrm{J}$ ). Journal of Northeast University of Finance and economics, 2020, (3): 90-96, cover three

[3] Game Analysis on the Lack of Credit of Operators in E-commerce Platform Sunxiaohan (Beijing Institute of materials, Beijing 101149)

[4] Ji Shujuan, Bao Chunxiao, sun Guanguan, Zhang Chunjin. Research on Seller's integrity game model in e-commerce platform [J]. Software guide, 2020,19 (03): 21-26

[5] Research on Counterfeit Selling in Enterprises Based on Evolutionary Game Theory, Zhao Chong, Guangdong University of Technology, Guangdong, Guangzhou, 510000

[6] Based on the theory of game, the phenomenon of counterfeit and shoddy products on e-commerce platform is discussed, Zhang Yang, School of Economics, Nankai University 